\title{
Una crónica del poder. Federalismo, reforma y gobierno dividido en México
}

\section{A chronicle of power. Federalism, reform and divided government in Mexico}

Fernando Pérez Correa• Eduardo Torres Alonso**

\section{Resumen}

El proceso de negociación política en México no ha sido sencillo. Se requiere voluntad y compromiso, a la vez que pragmatismo y racionalidad. Los actores que participan en la política persiguen intereses y para conseguirlos requieren participar en diálogos y encuentros con los otros. La reconstrucción del país después de la Revolución Mexicana fue una muestra de una negociación de amplio espectro. El federalismo, bandera enarbolada durante los combates revolucionarios, fue una demanda presente al inicio del nuevo Estado mexicano $y$ presente durante el siglo $x x$, que derivó en reformas constitucionales. En fin, la negociación política y el orden imperante cambió cuando el partido emanado de la Revolución perdió su hegemonía en el Poder Legislativo y se suscitaron nuevas dinámicas de cohabitación.

Palabras clave: Revolución Mexicana, presidencialismo, reformas, federalismo, negociación.

\begin{abstract}
The process of political negotiation in Mexico has not been easy. It requires willingness and commitment, as well as pragmatism and rationality. The actors involved in politics pursue interests and to achieve them they participate in dialogues and meetings with others. The reconstruction of the country after the Mexican Revolution was a sign of a broad-spectrum negotiation.The Federalism, a flag raised during the revolutionary combats, was a current demand at the beginning of the New Mexican State and during the twentieth century, originating constitutional reforms. In short, the political negotiation and the prevailing order changed when the emanated party from the Revolution lost its hegemony in the Legislative Power and new dynamics of cohabitation were promoted.
\end{abstract}

Keywords: Mexican Revolution, presidentialism, reforms, federalism, negotiation.

\footnotetext{
- Facultad de Ciencias Políticas y Sociales, UNAM._fernandoperezcorrea@yahoo.com.mx ORCID:0000-0003-090I-3783. - Facultad de Ciencias Políticas y Sociales, UNAM._etorres.alonso@gmail.com ORCID:0000-0002-0868-2240. Fecha de recepción: 21 de julio de 2020. Fecha de aceptación: 4 de febrero de 2021.
} 


\section{Introducción}

El debate sobre las causas que produjeron la Revolución Mexicana ha sido interminable (Ávila Espinosa, 2017; Womack, 2017; Aguilar Camín, 2017). Para explicar la génesis y el proceso del cambio de régimen que conmovió las raíces de México a inicios del siglo xx, se han invocado determinaciones estructurales y coyunturales, internas y externas, nacionales y locales; económicas, políticas y sociales (Silva Herzog, 2005; Brading, 1985; Knight, 2015; Barrón, 2004). A las discrepancias explicativas habría que añadir los más variados matices ideológicos (Meyer, 2016). Con todo, entre los pocos puntos de coincidencia que comparten historiadores, expertos y analistas de la Revolución, se encuentran el carácter múltiple, local y regional, tradicional y moderno de los conflictos que le dieron vida, así como el proyecto federalista y municipalista que articuló algunas de sus demandas.

En efecto, la lectura de la variada historiografía del movimiento revolucionario deja pocas dudas sobre el signo descentralizado de su geografía, real y simbólica: levantamiento periférico en oposición al centro, guerra de movimientos resuelta fuera de la capital, golpe de mano contra Madero en la Ciudad de México e insurrección nacional convocada desde la frontera; resistencia en el sur y movimiento envolvente desencadenado desde el norte; finalmente, guerra de facciones decidida en la periferia. El análisis del discurso revolucionario conduce a conclusiones análogas sobre el carácter de la Revolución: identificación del régimen central, sus agentes y los prefectos locales como los enemigos a vencer; adjudicación al centralismo porfirista de los males económicos, políticos y aun morales de la sociedad; supresión de los jefes políticos y algunos ministerios, y la afirmación de la soberanía de los estados y del municipio libre como demandas unificadoras. 
En este trabajo se discute el proceso histórico de construcción de un federalismo efectivo después de la Revolución Mexicana, señalando momentos y circunstancias de ésta, como ejemplo de un proceso de negociación política, y también delinea los procesos de reforma a esta manera de organización del poder a través de modificaciones constitucionales antes y durante el primer gobierno dividido presentado en México. En fin, en este texto se busca recopilar coyunturas, actores y procesos de la forma en que la política se procesa en el país.

\section{El origen}

La Revolución originó un gran discurso y un amplio movimiento descentralizador. La Convención Revolucionaria de Aguascalientes sumó a los jefes políticos al inventario de sus archienemigos: clérigos, hacendados y extranjeros (Alessio Robles, 2014). El Constituyente de 1916-17 no requirió de grandes debates para ajustar cuentas con el centralismo (Marván, 2017). Es cierto que el artículo 115 del nuevo "Pacto Federal" retomó del texto de 1857 la forma de gobierno de una república federal, "compuesta de estados libres y soberanos [...] unidos en una federación establecida según los principios de esta ley fundamental" (artículo 40). También es verdad que reprodujo el artículo 41, para subrayar que los estados contarían con su respectivo "régimen interior, en los términos [...] establecidos por [...sus constituciones] particulares [...], las que en ningún caso podrán contravenir las estipulaciones del pacto federal". Pero las reivindicaciones localistas fueron ampliadas. En efecto, la Constitución liberal había delineado la organización política de los estados al señalar que adoptarían "para su régimen interior la forma de Gobierno Republicano, Representativo y Popular". Como se advierte, el municipio no fue incluido entre las instituciones políticas distintivas, 
ya fuera de la forma de gobierno, o del régimen interior de las entidades federativas. Pero la Convención de Aguascalientes postuló la autonomía del municipio como uno de los objetivos unificadores de la Revolución. Y aunque la abrupta ruptura de las hostilidades enfrentó a convencionistas contra constitucionalistas, la causa municipalista ya había sido enarbolada. El 25 de diciembre de 1914, en plena lucha civil, Venustiano Carranza, primer jefe del Ejército Constitucionalista, decretó la reforma del artículo 109 de la Constitución, adicionándolo con la expresión "teniendo como base de su división territorial y de su organización política, el Municipio Libre, administrado por Ayuntamientos de elección popular directa y sin que haya autoridades intermedias entre éstos y el Gobierno del Estado". El decreto agregó precisiones sobre el mando de la fuerza pública y la no-reelección de los gobernadores.

Con este antecedente, en diciembre de 1916 Venustiano Carranza envió al Congreso Constituyente un proyecto para una nueva Constitución, en cuyo artículo 115 reprodujo el decreto comentado anteriormente, adicionado con la propuesta de diversas medidas, igualmente ya invocadas. El Congreso resolvió ir más lejos y se propuso fundamentar explícitamente la autoridad municipal. Como resultado, una vez postulado el "municipio libre", los constituyentes acometieron en tres apartados la tarea de instituir los atributos del nuevo orden de gobierno. El primer apartado reprodujo el decreto de 1914, mientras que el segundo y el tercero establecieron, a la letra, que:

II. Los municipios administrarán libremente su hacienda, la cual se formará de las contribuciones que señalan las legislaturas de los estados y que, en todo caso, serán las suficientes para atender a sus necesidades; III. Los municipios serán investidos de personalidad jurídica para todos los efectos legales. 
Con el tiempo, ambas adiciones se convertirían en el germen de lo que sería una verdadera Carta Municipal, y en fuente de lo que, después, se convertiría en la autonomía de los ayuntamientos.

Recordemos que desde 1914 se había asignado a los ayuntamientos la administración de los municipios y que para evitar la vuelta de los prefectos, se había dispuesto que no existiría "ninguna autoridad intermedia" entre el Ayuntamiento y el Gobierno del estado. Así quedó establecido el principio de no reelección inmediata de las autoridades municipales. Recordemos, también, que en 1917 los municipios fueron facultados para "administrar libremente su hacienda", formada por contribuciones que serían, en todo caso, "suficientes para atender las necesidades municipales". Los municipios fueron investidos de personalidad jurídica y sus autoridades recibieron el mando de la fuerza pública, salvo donde residieran el Ejecutivo federal o los gobernadores. Pero a estas premisas expresas deben sumarse diversas disposiciones dispersas que, en conjunto, diseñan un orden federal de tres pisos. En 1917 se reservaron nuevamente a los estados las facultades que no fueran expresamente atribuidas a las autoridades centrales. En el artículo 3, adicionalmente, la educación quedó confiada a los "establecimientos oficiales de educación". Sin embargo, el artículo 73 omitió cualquier referencia a la educación que permitiera asignarle un carácter federal, y el artículo 14 transitorio suprimió "las secretarías de Justicia y de Instrucción Pública y Bellas Artes”. En fin, las autoridades municipales y estatales recibieron la encomienda de atender diversas funciones determinantes en las nuevas materias agraria y laboral.

Volvamos al proceso movilizador que desató la Revolución. De pronto, los diversos estratos sociales y la población de las más variadas regiones del país se vieron envueltos en un gran movimiento nacional. Sin embargo, los resortes 
del encuadramiento fueron esencialmente regionales, de tal manera que hay simultaneidad en las cuestiones nacionales y las adhesiones locales. El despliegue geográfico del levantamiento maderista, que culminó en Ciudad Juárez; la fragmentación del país con motivo del cuartelazo huertista y el consecuente levantamiento, particularmente a lo largo de la campaña del Ejército Constitucionalista y la División del Norte (Urquizo, 1964; Salmerón, 2006), y los alineamientos regionales producidos por la guerra entre las distintas facciones revolucionarias que impulsaron y consolidaron el carácter anticentralista del programa revolucionario con el que nació la Revolución.

Como consecuencia, no fue sino hasta la organización de los grandes sectores sociales, durante el cardenismo, y con la gradual profesionalización del Ejército Nacional, que las fuerzas regionales dejaron de conformar el hilo conductor del poder político. La lucha por el poder se libró en toda la República, y la disputa de las facciones se encarnó en propuestas nacionales. Acaso por eso el proceso de reconstrucción del régimen mexicano dio paso a un sistema centralizado, cada vez menos fluido y flexible. El estudio comparativo de la evolución presupuestal de los gobiernos federal y estatales, el examen del proceso de reformas constitucionales, la descripción de la génesis de la Presidencia - convertida en epicentro de la República e integradora de la política y la sociedad, con base en un aparato administrativo en expansión y un partido integrador, altamente centralizado-y, desde luego, el análisis de la inversión, la producción y el empleo en acelerada concentración en el centro, arrojan un resultado inequívoco: el régimen político y la organización social cobraron la forma de un centralismo agobiante (Carpizo, 2002; Salazar Ugarte, 2017). 


\section{Centralismo y federalismo: el ciclo falseado}

$\mathrm{Al}$ inicio de la Revolución, un consenso anticentralista inspiró la profundización del federalismo y el municipalismo. Quizá todos los actores políticos compartieran de buena fe este objetivo. Sin embargo, el régimen revolucionario perseguía objetivos contradictorios. Entre éstos sobresalía el programa social. Pero la puesta en marcha de ese régimen se tradujo en un amplio mandato constitucional que convirtió al presidente en un núcleo hiperdotado de facultades (Hurtado, 2001; Pozas Horcasitas, 2004; Mendoza Berrueto, 1996). Peor aún, la consolidación del nuevo régimen (y su apetito expansivo) implicó una revisión sistemática de la Constitución, cuyos efectos fueron, casi invariablemente, centralizadores: las reformas han modificado las garantías individuales (y los procedimientos que las tutelan), los derechos sociales (para multiplicarlos en el ámbito declarativo), la atribución de nuevas facultades a los poderes, y la instauración de procedimientos y mecanismos de gobierno.

\section{La línea titubeante}

A partir de la crisis de 1982, con la adopción de la agenda sobre la Reforma del Estado, se inició en México una sistemática reforma federalista y municipalista. "Descentralización de la vida nacional" se llamó una de las siete tesis del gobierno lamadridista. Como es sabido, la reforma del artículo 115 constitucional, de febrero de 1983, modificó sustancialmente la organización municipal. Se reguló la suspensión de los ayuntamientos. Con ello el procedimiento respectivo perdió algunas de sus características más brutales, autorizadas por las constituciones locales. Se ampliaron las atribuciones de los ayuntamientos para dotarlos con la facultad reglamentaria y atribuirles la prestación de los servicios públicos municipales, la regulación del uso del 
suelo y la planeación del desarrollo urbano. De particular significación fue la asignación exclusiva a los municipios de los ingresos prediales e inmobiliarios que serían recaudados por los ayuntamientos sin excepciones. Además, la reforma hizo explícito a favor de los ayuntamientos el pleno reconocimiento a su personalidad jurídica y los capacitó para administrar libremente su hacienda. Finalmente, los facultó para concertar convenios de asunción gradual de servicios públicos y de colaboración con una variedad de instancias: otros municipios y el gobierno estatal.

Sin duda estas modificaciones respondían a múltiples aspiraciones y presiones locales, como también a cierto reformismo ilustrado. Pero se produjeron en un marco complejo, a menudo crítico y siempre con presiones encontradas. Por calificarlo de alguna manera, tuvieron un carácter democrático compensador en la coyuntura de una crisis devastadora. Las modificaciones obedecían más a la necesidad de fortalecer la legitimidad del régimen, que a la atención de una demanda irresistible. La consecuencia fue inevitable. A las múltiples resistencias y fricciones que generaron, se adicionaron los efectos contrarios de otras reformas emprendidas simultáneamente. Las nuevas bases aprobadas en 1983 incluyeron un artículo transitorio que impuso a los congresos locales la modificación constitucional y legal pertinente para adaptar sus normas, en el plazo de un año, a los nuevos principios municipalistas. A pesar de todo, la reforma tardó en arraigarse y sólo de manera lenta y titubeante alteró las relaciones locales de poder.

En las postrimerías del régimen zedillista, el artículo 115 fue modificado nuevamente, con el renovado propósito de fortalecer la organización municipal. La reforma sistematizó algunos aspectos técnicos vinculados con el patrimonio y las finanzas municipales, y enriqueció sin cambios dramáticos el texto del 83. Nuevamente, se trató de una reforma ilustrada, que respondía más a las insuficiencias políticas 
y programáticas de los ayuntamientos, que a las grandes demandas sustentadas en fuerzas o movimientos decisivos.

Desde luego, las entidades federativas (estados y, en ese momento, Distrito Federal) no quedaron exentas de un esfuerzo reformista análogo. En efecto, en paralelo a los cambios municipalistas, la Constitución experimentó un proceso de reformas "federalistas", emprendidas acaso con un ánimo reparador, ante el despiadado (y continuado) saqueo de las facultades de los estados a favor del gobierno central. Al respecto, conviene destacar la gradual transformación del Distrito Federal, que de ser un "departamento administrativo" del gobierno federal, se ha convertido gradualmente en una entidad federativa. Pero dicho proceso ha tenido esencialmente un objetivo ordenador de las normas que regulan a los estados y al Distrito Federal, hoy Ciudad de México. Las primeras fueron reagrupadas en los artículos 116 al 121, donde se sistematizaron, en particular en el primero de ellos, diversas disposiciones hasta entonces dispersas en otros artículos; mientras tanto, las normas relativas al Distrito Federal fueron objeto de un extenso tratamiento regulatorio en el artículo 122. Pudiera pensarse que la reafirmación de los principios del federalismo, y el reconocimiento del estatuto de la capital de la República como entidad federativa, favorecerían una vuelta irresistible al proyecto federalista.

Como en el pasado, iniciativas simultáneas y propósitos opuestos han complicado nuevamente las cosas. Y al lado de cada reforma federalista pueden identificarse muchas otras centralizadoras, justificadas o no. Pero, por encima de estas incongruencias, la razón de fondo del titubeo entre centralización y descentralización se sitúa en las tareas que implica la construcción de una democracia nacional moderna.

El federalismo cuenta con una vocación histórica que se remonta a la etapa fundacional del país (Mejía Garza 
y Rojas Zamudio, 2018). Es cierto que por medio siglo las Constituciones mexicanas oscilaron entre el centralismo y el federalismo, alternativas orgánicas que se sucedieron a golpes de cuartelazos y guerras civiles, hasta que la República fue definitivamente restaurada. Entonces el régimen federal ofreció una vez más un espacio para el desarrollo de élites locales y regionales. Sin embargo, la reciente intervención y la guerra civil habían demostrado que, sin la consolidación del Estado nacional, serían inevitables nuevos desprendimientos y mutilaciones. Lo cierto es que, al concluir el siglo, ya estaba en marcha el proyecto de consolidación nacional del Porfiriato. Fue un proceso secular: en buena medida a lo largo del siglo XIX y hasta su conclusión, el gobierno federal fue una síntesis frágil de realidades y aspiraciones locales, articuladas por alianzas inestables entre fuerzas nacionales fragmentadas. Y, aunque suene extraño, una de las contribuciones decisivas del régimen federal fue impulsar, gradualmente, la construcción del Estado y las instituciones nacionales, a expensas desde luego, "de la libertad y soberanía" de los estados.

En contrapartida, la extrema desigualdad entre las personas y las regiones reclamaba contar con mecanismos compensatorios, equilibradores, de modo que los abismales extremos no se profundizaran y fuera posible repararlos. Como en tantas otras cuestiones sociales, en este ámbito se buscó integrar a la nación en un todo simultáneamente diverso y unido. De ahí que los poderes centrales no tuvieran mucho reparo en apropiarse de funciones municipales, al tiempo que "impulsaban" el federalismo. Lo cierto es que, en todos los niveles, y contra las intenciones expresas, el gobierno federal buscó ensancharse y concentrarse. En la práctica, la Revolución dejó definitivamente atrás la propuesta centralista. Y, sin embargo, una vez victoriosa, la organización federal fue objeto de reformas pendulares. Desde la primera reforma constitucional posterior a 1917, 
que restableció el carácter federal de la educación, han sido incontables las enmiendas tendentes a trasladar del ámbito periférico al central diversas competencias. Acaso en los años iniciales de la postrevolución, el cumplimiento del programa social contenido en el pacto federal justificara las primeras iniciativas centralizadoras. Pero lejos de ser un fenómeno pasajero, con el tiempo se multiplicaron las iniciativas "federalizadoras". Entre éstas destaca la adopción de un sistema hacendario centralizado introducido como resultado de reformas inspiradas en la "coordinación fiscal" y, en muchos casos, programadas en el seno de las convenciones nacionales fiscales. Pero no fue la única. Otras más desencadenaron efectos análogos. Baste recordar entre ellas el crecimiento del sector paraestatal federal, hasta el extremo de dar cuenta de una proporción exorbitante del producto interno bruto nacional; la expansión de la globalización y su impacto en las economías locales, y las distorsiones que produjo la concentración del poder en la Presidencia de la República y sus instrumentos de gobierno.

En suma, a lo largo del siglo xx, ni los estados ni los municipios dispusieron de condiciones políticas favorables para oponerse a la centralización. Peor aún, los municipios carecieron hasta la última década de recursos jurídicos para defender sus atribuciones y su vocación gubernativa. Pero el proceso concentrador no fue homogéneo.

\section{Todo sigue igual}

El proceso de centralización se sostuvo y se expandió inexorablemente, incluso como resultado de iniciativas que no se propusieron alentarlo. La Reforma del Estado emprendida en nuestro país a partir de la década de los ochenta del siglo xx, por ejemplo, se ha propuesto fortalecer la vida local. Sin embargo, visto como un proyecto integral de modernización, tendente a fortalecer a la sociedad frente 
al Estado; a los poderes Judicial y Legislativo frente a la Presidencia, y a los órdenes municipal y estatal frente al federal, ha arrojado, en la práctica, un balance centralizador. Las materias de mayor interés circunstancial —como los procesos electorales y la seguridad pública—, los ámbitos de mayor dinamismo — como la apertura comercial—, y las modificaciones orgánicas, incluso las de corte municipalista, todas ellas desencadenaron efectos de un decidido tono centralizador.

Acaso la contradicción más sorprendente se produjo en 1995, cuando la Cámara de Diputados estableció en el Presupuesto Federal de Egresos los montos y los criterios de asignación de las transferencias federales destinadas a los ayuntamientos. Con este procedimiento la Cámara asignó directamente los recursos municipales, e hizo caso omiso de las facultades constitucionales de los congresos locales $\mathrm{El}$ incremento sustancial de los montos federales destinados a los estados, vía las asignaciones a los municipios, tuvo un indiscutible tono descentralizador. Sin embargo, terminó por propiciar un enfrentamiento entre los poderes centrales y estatales, cuando los métodos de la Cámara (asignaciones directas a los municipios, vía el presupuesto federal) contravinieron claramente las competencias constitucionales de las legislaturas, competentes para asignar las "participaciones federales" a los municipios, de acuerdo con "las bases, montos y plazos" que ellas fijen. La medida vulneró entonces la capacidad de éstas y tuvo un efecto centralizador.

Por otra parte, la transparencia y certidumbre de los procesos electorales ha sido una demanda central de las últimas décadas. Sin embargo, el procedimiento adoptado para avanzar implicó, en última instancia, la centralización de los procesos jurisdiccionales establecidos para resolver las impugnaciones electorales y zanjar las discrepancias. Al margen de las razones que pudieron inspirar la instauración 
de un procedimiento federal, en esencia se trató, como en el tema precedente, de una iniciativa cuyo balance final fue centralizador.

\section{La reforma del Estado y la reforma del régimen federal}

En julio de 2000, con el triunfo de Vicente Fox en las elecciones presidenciales, se confirmó la conclusión del casi centenario régimen de partido hegemónico. Dicho fin ya había sido anunciado en 1997, con la integración de un Congreso dividido. En el 2000, los electores expresaron una clara voluntad de cambio. El Partido Revolucionario Institucional no alcanzó las dos quintas partes de los votos. Ganó Fox. Seducidos por el estilo fresco del candidato de la Alianza por el Cambio, convencidos con el argumento del voto útil, y deseosos de construir "otra cosa", los votantes le asignaron una mayoría relativa.

Vicente Fox había sido gobernador de Guanajuato cuando defendió con gallardía las tesis descentralizadoras. En el 2000 fue un candidato federalista. Ofreció un nuevo régimen, una nueva relación entre el Ejecutivo federal y los poderes locales, el fin del presidencialismo.

Pero las cosas siguieron otra ruta. Fueron tres los documentos centrales con los que arrancó el gobierno del cambio. Uno es la exposición general de la propuesta de la Nueva hacienda pública distributiva. Otro se titula: Porque es lo justo y explica con ánimo persuasivo las grandes líneas de dicha propuesta. El tercero es la Exposición de motivos de la iniciativa de reformas legales que el nuevo presidente envió al Congreso de la Unión. El primer documento fundamenta el propósito de generar nada menos que "un nuevo marco tributario, equitativo, competitivo y eficiente, y un sistema financiero más sano, capaz de canalizar eficientemente el ahorro [...]". Dicho objetivo reclama, afirma el presidente, una reforma "integral”. El documento explica con razón los 
defectos del sistema imperante (inequidad, ineficiencia, insuficiencia, complejidad, arbitrariedad y debilidad de la recaudación). Con una retórica convincente, el texto dedica ocho párrafos al rechazo de la situación vigente. "Nadie puede sentirse satisfecho con el dinamismo y la naturaleza del crecimiento económico que hemos logrado como país. No podemos resignarnos [...], nadie puede considerarse satisfecho [...], no podemos evadir la realidad [...]". El documento subraya cuatro veces que "no podemos cerrar los ojos", tres veces que "no podemos evadir la realidad", y dos veces que "no podemos ignorar". Aunque no necesariamente surge de los males descritos, la conclusión es una convocatoria apremiante: requerimos "de un cambio de raíz en el monto y en la estructura de los ingresos públicos, de una mayor transparencia en el ejercicio del gasto y de un sistema financiero promotor del desarrollo". Son tres las vertientes de la reforma propuesta: "adopción de un nuevo marco tributario, reforma presupuestal y reforma financiera". Ahora bien, volviendo al tema, en todo el documento no hay una línea que proponga un nuevo federalismo tributario, que convoque a una nueva convención fiscal nacional, que señale algún protagonista de este nuevo orden que no sea el Gobierno federal. La única mención a los otros órdenes del gobierno es la promesa de

[...] fortalecer la capacidad de respuesta de los gobiernos estatales y municipales para atender las necesidades crecientes en materia de gasto social e inversión pública,y [nótese el inexplicable salto temático] para mejorar la transparencia del gasto público, fortalecer la rendición de cuentas y mejorar la calidad del gasto público.

El segundo documento, Porque es lo justo, explica simplificadamente la esencia de la reforma tributaria. Entre los protagonistas y los caminos propuestos no se encuentra la participación de los estados, el nuevo papel que éstos 
desempeñarán en el nuevo sistema, las medidas tendentes a fortalecer su autonomía financiera. En un listado de las "medidas" que implica la "reforma tributaria distributiva", entre diversos capítulos y acciones, se advierte apenas la siguiente mención: "Derrama a estados y municipios [...]"; nada más. Igual ocurre con el tercer documento, la Exposición de motivos de la reforma hacendaria. Es notoria la ausencia de una metodología para generar un nuevo consenso tributario federal, la definición del nuevo papel que corresponde a los estados en el sistema propuesto, y las competencias estatales que pondrán término al presidencialismo. Diríase que en el nuevo régimen el proyecto federalista quedó, en los hechos, como una quimera liberal y decimonónica.

Sin embargo, si volteamos hacia los amplios espacios de la interacción política nacional, se puede advertir la instauración, si no de un nuevo federalismo, sí al menos de nuevas relaciones de poder entre el centro y las regiones. Pero esta vez el fortalecimiento de éstas y el nuevo impulso de los estados y municipios no es el resultado de un proyecto democrático ilustrado, es el efecto inescapable del pluralismo y la cohabitación. Hoy son más que decenas, centenares, las controversias constitucionales que, en los últimos años, los ayuntamientos han planteado en todo el país contra otros poderes, en particular contra los gobernadores. Son incontables también las controversias que los gobernadores han planteado ante el Poder Judicial federal en contra del presidente. Entre las más célebres destaca la disputa entre el jefe del Gobierno del Distrito Federal y el presidente sobre quién tiene derecho a establecer los husos horarios. Para el asombro de ambos, la Corte resolvió que dicha competencia corresponde al Congreso. Incluso, el Senado ha recurrido a dicho expediente constitucional para cuestionar decisiones del Ejecutivo federal, como fue el caso en el que impugnó la constitucionalidad del reglamento de la industria eléc- 
trica. En suma, la existencia de un instrumento eficaz de cuestionamiento de las decisiones del centro ha dotado a los poderes locales y a los municipios de un recurso eficaz para defender su autonomía, es decir, para dar vida auténtica al principio animador del federalismo.

En diciembre del año 2000 los gobernadores asistieron a la toma de posesión del presidente Fox y se quedaron el tiempo necesario para rendir honores y solicitar favores. Fue sorprendente advertir que fueron los mandatarios panistas (de Nuevo León y Querétaro, por ejemplo) quienes cuestionaron o resistieron los halagos del presidente. Pero, al poco tiempo, las cosas habían cambiado sensiblemente. Con motivo de la entrega de recursos federales asignados a los estados y municipios, se multiplicaron las discrepancias. Los gobernadores expresaron su descontento con el centro en materias tan diversas como la construcción de caminos, la orientación de la política social, o la intervención de la Policía Federal Preventiva o de la intromisión de otras agencias centrales en asuntos locales. La realización de fiestas cívicas promovió la articulación de acciones conjuntas de los ejecutivos locales, al mismo tiempo "enérgicas y respetuosas". En este proceso destaca el 13 de julio de 2001. Ese día nació en Cancún la Conferencia Nacional de Gobernadores (Conago), "foro de concertación" a partir del cual los ejecutivos locales han planteado demandas al presidente de la República. A falta de mejores canales, los organizadores de dicha Conferencia constituyeron un espacio de negociación y acuerdo entre los jefes del Ejecutivo local y federal. El objetivo era contar con un foro único, determinante. Parece prácticamente ilimitado el potencial de un foro de acuerdo entre el presidente y los gobernadores; es decir, entre las instituciones y las fuerzas que uno y otros representan. Por eso, sorprendió el recelo, si no la renuencia del Gobierno federal, a compartir la construcción de nuevos espacios 
donde puedan identificarse los interlocutores y las discrepancias y lograr acuerdos sobre las políticas de Estado.

El acotamiento contemporáneo del presidencialismo es claramente obra del pluralismo democrático. Se trata de un cambio trascendente que, por cierto, no es gratuito para los protagonistas. La nueva fuerza del Poder Legislativo ha significado repetidos asaltos violentos a la sede de la Cámara de Diputados. De manera análoga, el multipartidismo que expresan los gobernadores atribuye a éstos no sólo el privilegio de compartir los beneficios de un gasto más holgado, sino también los costos de participar en la tributación y la recaudación fiscal.

La inercia del centralismo cobró sus tributos a lo largo del sexenio del presidente Fox. El combate (real o supuesto) a la corrupción (real o supuesta), el ánimo ilustrado de los funcionarios federales por hacerse cargo del desarrollo local, y el impulso modernizador de Gobierno federal, aconsejaron el veto a la Ley de Desarrollo Rural, desde los primeros días del gobierno y justificaron la concertación de un nuevo texto. El resultado concreto fue la centralización adicional en la asignación de recursos para el campo. La incuria del sistema de salud es sublevante; sin embargo, es la expresión de las insuficiencias de la descentralización a medias; es decir, de aquella que no parte del montaje de servicios locales bien armados y suficientes. Se subrayan los extremos a los que se llegó en 2002: frente a una emergencia, el Gobierno de Chiapas aceptó el apoyo de Cuba y rechazó el de la Federación. En el otro extremo, en Chihuahua el Gobierno estatal y la Policía Federal Preventiva dirimieron en la prensa sus recíprocos agravios. Admitamos que una cierta "voluntad de poder" ha inspirado desconfianza y recelo y no ha contribuido a fomentar el acuerdo. 
La alternancia y el gobierno dividido. Discusiones y problemas

En 1997 se produjo un paso decisivo en dirección de la alternancia en los poderes federales (Casar y Malvar, 2002). Las elecciones de ese año resultaron en la integración de una Cámara de Diputados dividida. Por primera vez, desde la creación del partido de la Revolución, el presidente de la República no tendría mayoría legislativa y, como consecuencia, tampoco contaría con un Congreso disciplinado. Cierto, con 239 curules, el PRI obtuvo al menos la mayoría relativa. Pero estaba en minoría, y no contaba con privilegio alguno contra la extravagante idea de sus diputados electos, según quienes la mayoría relativa que alcanzaron les otorgaría el supuesto derecho a encabezar la formación de una coalición mayoritaria. Pero muy pronto se agolparon los descalabros. Finalmente, el hasta entonces invencible sufrió una derrota tremenda: quedó marginado de la organización interna de San Lázaro y arrinconado al intentar desplegar su propia agenda legislativa.

Sin embargo, al concluir la elección de 1997, el PRI no tenía todo perdido. Es cierto que la suma de minorías, aunque vista como una remota posibilidad teórica, tenía todo el potencial para convertirse en un bloque mayoritario. Pero esa posibilidad acicateaba al PRI para trabajar, pactar y consolidar acuerdos parlamentarios. Para hacerlo era necesario asumir la derrota y, desde la perspectiva de una minoría, hacer política. Desde el 31 de julio se prendieron las luces rojas. Entonces las "cuatro minorías" expresaron su voluntad de constituir "un contrapeso frente al Ejecutivo" y promover "cambios en la política económica". Los voceros de la nueva oposición, reunidos con el sector empresarial (encabezado en esa época por Eduardo Bours, entonces gobernador priísta de Sonora), fueron Felipe Calderón Hinojosa y Andrés Manuel López Obrador. Por su parte, 
el mismo día los coordinadores de las nuevas bancadas del Partido Acción Nacional, del Partido de la Revolución Democrática y del Partido del Trabajo (Medina Plascencia, Muñoz Ledo y Gonzalo Yáñez, respectivamente) interpretaron la correlación de fuerzas en la Cámara, nada menos que como un claro mandato popular a favor de una nueva política económica. El aviso era apremiante. Pero, en lugar de hacer política, la bancada oficial esperó a que las circunstancias restablecieran "la proporción de las cosas".

Pero eso no podía ocurrir espontáneamente así. Las señales eran clarísimas. Eran concebibles diversos escenarios para el inminente 1 de septiembre, día en que la nueva Legislatura quedaría instalada y el presidente Zedillo presentaría su tercer Informe. Con el PRI en minoría de 11 votos, y cuatro partidos de oposición con 261 curules, era posible una infinidad de combinaciones. Destaco tres modelos rivales: la oposición unida, el gobierno de coalición y el bazar cotidiano. En efecto, era posible un acuerdo que concretara un bloque de oposiciones; la puerta estaba abierta también para que el PRI encabezara un bloque con fuerzas suficientes que le aseguraran la mayoría, o bien, no se excluía el hecho de que se configurara una situación volátil e incierta, destrabada temporalmente por acuerdos efímeros y bloques pasajeros circunstanciales. Si el PRI aspiraba a encabezar una coalición, le aguardaba un intenso trabajo de negociación. Ignoro si lo emprendió, en cuyo caso lo hizo claramente de una manera insuficiente o ineficaz.

Lo cierto es que las minorías se organizaron y trabajaron duro, y el 11 de agosto hicieron público su compromiso de construir un bloque mayoritario. El "Acuerdo de gobernabilidad" que suscribieron ese día los representantes del PAN, PRD, PVEM y PT (el Grupo de los Cuatro) está lleno de enseñanzas. En primer término, porque fue el fruto de varios años de trabajo previo, compartido por sus promotores, en el proceso de la reforma electoral "definitiva" pactada en 
la Legislatura precedente. En efecto, en las negociaciones del Acuerdo participaron varios veteranos del "Grupo San Ángel”, el seminario del Castillo de Chapultepec, las conversaciones de la casa de Barcelona, las mesas del Diálogo Político Nacional, y las negociaciones para la nueva Ley Electoral. No en vano la reunión final se celebró en la casa de Santiago Creel, consejero del Instituto Federal Electoral apenas unos meses antes, e inminente presidente de la Comisión de Puntos Constitucionales de la Cámara.

Estos innovadores de la oposición se encontraron frente a una fracción inflexible y "digna”, que pensó que podía amedrentar a los partidos con el peso del Ejecutivo, y que era imposible una alianza funcional y perdurable entre el agua y el aceite. Como era de esperarse, la mayoría pactada se comió vivos a los del PRI.

Otra enseñanza del Acuerdo fue su naturaleza procedimental: no fue, en rigor, un acuerdo sustantivo y las partes no concertaron alguna línea de política económica o social. El pacto fijó las reglas del juego consistentes, en lo esencial, en sujetar al tricolor precisamente a su condición de minoría. Es asombroso, por ejemplo, que incluso los partidos se hayan comprometido, en documento anexo, a no sostener reuniones "bilaterales" con el PRI en los días siguientes, "a fin de evitar cooptaciones y mantener el acuerpamiento de los compromisos asumidos".

Los puntos del Acuerdo de gobernabilidad fueron cinco: 1. Rescatar la dignidad e independencia del Poder Legislativo (lo que significaba dar paso a una Cámara plural, capaz de "resistir al presidente"); 2. Integrar de forma paritaria el órgano de gobierno de la Cámara y hacer rotativa su presidencia (es decir, designar la Comisión de Régimen Interno y Concertación Política, precisamente con los cinco coordinadores de las fracciones parlamentarias y asignar la presidencia anual de dicha Comisión - y de la Cámara-consecutivamente a un partido de oposición - el 
PRD—, al partido en el gobierno - el PRI-, y a otro partido de oposición —el PAN); 3. Modificar el formato del Informe Presidencial (con la intención de asignar después de la lectura, 15 minutos a cada coordinador, y encomendar a un diputado la lectura de un texto "breve y republicano"); 4. Integrar las comisiones de una manera proporcional (es decir, en términos que reflejen la fuerza de las fracciones, e impedir su control por un solo partido); 5. Ciudadanizar a los funcionarios y administradores y designarlos por consenso (con la idea de evitar una gestión partidista o sesgada). A este acuerdo se adicionó la iniciativa de apremiar al PRI a sumarse a sus cinco puntos, en 48 horas y, en caso contrario, recurrir directamente al presidente para negociar con el formato del Informe. También se convino, como ya se afirmó, "evitar las negociaciones bilaterales".

El Acuerdo fue un duro golpe. El PRI declaró que no aceptaba negociaciones "en bloque", que no estaba "ni manco ni tullido", que no bailaría al "son al que nos toquen", y que no aceptaba los cambios ilegales al formato del Informe. Días después, el 13 de agosto, añadió que rechazaba "toda forma de negociación [...] arbitraria y unilateral". Sus voceros denunciaron después el "monolitismo" del bloque opositor y reclamaron la integración proporcional de la Comisión de Gobierno. Más tarde defendieron el viejo formato del Informe y rechazaron nuevamente, por ilegal, su modificación, mientras llamaban a defender "los principios", y no a la búsqueda de "mayorías coyunturales". Hubo incluso diputados que llamaron a no asistir al Informe Presidencial.

Pero fue en vano. El voto estaba del lado del bloque opositor y sólo una crisis constitucional podía impedir su ascenso al control de la Cámara. La ilusión priísta de que la coalición quedaría desvanecida no cobró forma. Al contrario, las partes del Acuerdo se negaron a negociar "bilateralmente". Por último, el tricolor aceptó discutir el gobierno de la Cámara y el formato del Informe. Y como 
estaba en minoría, se resignó a la conseja del agraviado: "de lo perdido lo que aparezca".

Pero el lance fue difícil. El día 29, rotas las pláticas, el bloque decidió (con los votos en la mano) instalar la Cámara, mientras el PRI, invocando su atributo de "mayoría relativa", amenazó con hacer lo mismo (sin contar con otra mayoría que la imaginaria). De hecho, la Cámara fue convocada por el bloque opositor a instalarse el sábado 30, a las 10 de la mañana, y por el grupo tricolor el 31, a las cinco de la tarde. La primera convocatoria resultó eficaz, y la Cámara se instaló el 30, en medio de obstáculos y tropiezos. En esas condiciones, era extravagante insistir en atender la segunda convocatoria, el 31, para instalar una Cámara que ya incluso había rendido la protesta. Pero el empeño por resistir era obcecado y produjo el humillante "enchiqueramiento" de los legisladores priístas (para tenerlos a la mano) y la posterior indignación de éstos frente a los resultados.

Fueron días de desconcierto y tensión extrema. Los dirigentes tricolores contaban con supuestas defecciones y rupturas, mientras sus colegas senadores soñaban con no presentarse al Informe e impedir, consecuentemente, la integración del quórum legal del acto. Finalmente intervino el presidente Zedillo para allanar el camino a la negociación. En realidad, ya integrada la Cámara y consumada su toma, el presidente impuso un acuerdo a la bancada recalcitrante. La instalación realizada por el bloque opositor fue convalidada, aunque los tricolores se negaron a tomar la protesta ante Muñoz Ledo, cuya Presidencia fue reconocida. A cambio se respetó la legalidad en el formato del Informe y el PRI obtuvo un sitio dentro de los órganos de la Cámara. La crisis constitucional quedó despejada y, como todos sabemos, fue memorable el acto en que el presidente pronunció su tercer Informe y Muñoz Ledo leyó su repuesta.

Sin embargo, los problemas apenas comenzaban. Una vez iniciados los trabajos legislativos, repartidos los pues- 
tos, recursos y prerrogativas; en fin, concluidos los festejos de unos y otros, se planteó una gran interrogante: ¿cómo construir los acuerdos necesarios para emprender grandes reformas estructurales o, más modestamente, aprobar al menos el presupuesto y los trámites de forma? En estos términos se inició (y prevalece hasta nuestros días) un juego pendular que ha pasado por los tres modelos de funcionamiento parlamentario descritos: la oposición unida, el gobierno de coalición y el bazar de coyuntura.

\section{El bazar de los acuerdos}

Con la instalación de una Cámara de Diputados dividida se inició una transformación inexorable del sistema mexicano. Desde luego, con el cambio de administración, las dificultades se hicieron sentir en la Cámara desde el primer momento. La fiesta del presidente, es decir, el Informe presidencial (las listas de asistentes, la atención a invitados, el control del recinto y su acceso, la comunicación social) había escapado de las manos del Estado Mayor Presidencial y era competencia del liderazgo compartido. El gobierno interno había cambiado de manos. Quien quisiera asistir tenía que convencer a Porfirio Muñoz Ledo. Pero el relevo no fue fácil. Todavía a finales de octubre, los diputados se quejarían del desorden administrativo, la falta de eficacia de la gestión y el sesgo discriminatorio con el que fluían los recursos. Y es que, como se recordará, a pesar de décadas y décadas de hegemonía priísta, después de todo el órgano legislativo era formalmente autónomo frente al Gobierno federal. Con la nueva legislatura, era la oposición quien atendía a la prensa, contactaba a las autoridades federales y expensaba el trabajo parlamentario. Por eso, en respuesta a los cargos de ineficacia, el nuevo gobierno camaral simplemente recordaba los interminables abusos y abandonos durante la casi secular gestión tricolor. 
Con todo, las dificultades para tramitar las cuestiones de sustancia eran más agudas. El despegue de la nueva Cámara no pudo haber sido más difícil. Como se recordará, apenas un día antes de la lectura del Informe, el domingo 31 de agosto la Presidencia de la República había emitido un comunicado. En él aclaró que el diálogo con el Poder Legislativo sólo podría ocurrir una vez resuelta la controversia sobre la instalación de la Cámara de Diputados, cuya constitucionalidad fue cuestionada por la mayoría del Senado de la República. No fue sino hasta el último momento cuando se llegó a un acuerdo. Los priístas, encerrados en el anexo de su sede, y con repetidas dificultades para abordar el autobús e instalar su propia Cámara, fueron advertidos de que tomarían la protesta el lunes en la mañana, ante la "cámara espuria", y que el Congreso sesionaría a las cinco de la tarde y que el jefe del Ejecutivo rendiría su informe a las ocho de la noche.

El inicio de la LVII Legislatura fue tenso. "Reproches, gritos, puñetazos en la Cámara [...]” tituló Proceso a su nota principal del 14 de septiembre. Se refería al enfrentamiento entre diputados del PRI y de la oposición, a la descalificación de las oposiciones al secretario de Gobernación, rechazado como interlocutor, y a las dificultades que confrontaba ya el secretario de Hacienda para establecer una comunicación fluida con la Cámara, frente a la tarea impostergable de debatir el paquete fiscal.

La agenda legislativa tardó en ser acordada y, en rigor, no pudo desahogarse a lo largo de los siguientes tres años. Los avances legislativos eran lentos y accidentados. Para finales de 1997 se planteaba con la mayor urgencia una cuestión periódica que no admitía dilación: la aprobación del presupuesto federal, proceso que debía consumarse antes del 15 de diciembre, fecha en que, según la legislación entonces vigente, concluiría el primer periodo de sesiones. A finales de octubre no habían avanzado los esfuerzos por construir 
un acuerdo. La edición de Proceso del 26 de octubre de 1997 es reveladora. En un mullido sofá están sentados, de izquierda a derecha, Porfirio Muñoz Ledo, sonriente y pensativo; Carlos Medina Plascencia, carcajeándose sin inhibiciones, y Arturo Núñez quien, receloso, concedió la sonrisa para la foto. El título es igualmente significativo: "La hora de la verdad, disputa por el futuro". Las entrevistas a dichos personajes contienen reproches y descalificaciones recíprocas, y el canónico compromiso de asumir con responsabilidad el significado de los nuevos tiempos.

El camino que condujo a la aprobación del presupuesto fue largo y tortuoso. A principios de noviembre los funcionarios de Hacienda se quejaron de la aspereza de la oposición. A lo largo de más de 20 encuentros con los diputados, concluyeron: "no hemos registrado ninguna coincidencia". Los obstáculos se advertían en dos renglones, los ingresos y el gasto. Respecto a los ingresos, la oposición exigía la reducción del IvA y la supresión de impuestos. En compensación, ofrecía gravar el consumo suntuario y reducir el gasto burocrático mediante la supresión de diversas secretarías, entre ellas Reforma Agraria, Turismo y Contraloría. Como era de esperarse, fue un asunto salpicado de propaganda, con la obvia intención de involucrar a la opinión pública y comprometer los sentimientos de los causantes en el tema. A lo largo de un mes las autoridades de Hacienda discutieron el punto con los partidos. No hubo acuerdos. A la postre, el Gobierno salvó su posición mediante un recurso práctico: neutralizó las decisiones de los diputados opositores, apelando a la misma moneda: el acuerdo adverso de la mayoría tricolor en el Senado. La Cámara Alta rechazó dos veces el proyecto de los diputados de reducir el IVA. Este impuesto representaba para el Gobierno la más sólida fuente fiscal de financiamiento del gasto público, ya que $40 \%$ de los egresos se pagaban con petróleo y el impuesto sobre la renta (ISR) representaba una fuente costosa, de recaudación difícil y 
de fugas interminables. Por lo demás, para el Ejecutivo era una cuestión de principio, inconmovible, mantener en $1.25 \%$ el déficit del gasto público, mientras el sol azteca proponía elevarlo a $3 \%$ y los blanquiazules guardaban un silencio neutral.

También del lado de los egresos el Gobierno confrontaba constreñimientos graves. La nueva Cámara demandaba una ampliación significativa del gasto social (cuestión de principio para el PRD), un apreciable incremento en los fondos transferidos a los gobiernos estatales y, sobre todo, municipales (reivindicación central del PAN). Simultáneamente, el financiamiento de las pensiones implicaba ya una erogación cercana a 1.5\% del PIB; mientras que el saneamiento financiero traía consigo una deuda pública monumental, como resultado de los polémicos rescates bancarios y carreteros. En suma, era necesario aumentar los ingresos y, para lograrlo, no había un asidero esperanzador. Por una parte el bloque opositor, o como fue fugazmente llamado, el "Grupo de los cuatro" (G-4), se había esfumado; por otra, la disciplina interna del PRI crujía sin cesar, en particular como resultado de las presiones de los legisladores del sector obrero.

Para todos los observadores resultaba obvio que no podría haber una salida de consenso. Y el Gobierno y el PRI (como habría de ocurrir tres años después con el gobierno del PAN) buscaron formar una alianza mayoritaria. Según La Jornada, el secretario de Hacienda se reunió con los dirigentes del partido del sol azteca. En tres larguísimas sesiones les ofreció ajustes sustanciales en la política social, a cambio de un acuerdo que dejara inalterada la política de ingresos; es decir, el monto del IVA y el sistema del impuesto sobre la renta en su conjunto, aunque en este último podría haber ajustes e incluso cambios de importancia. Pero los voceros del PRD no hicieron suyas las propuestas gubernamentales. Como resultado, la reunión del Gobierno con los legisla- 
dores perredistas, de suyo difícil, resultó en un rechazo estruendoso a una alianza entre ambas fuerzas. Fue una "cuestión de principios", explicaría más tarde Muñoz Ledo, cuyo pragmatismo resultó reprobado.

A finales de noviembre el PRI volvió la vista hacia el PAN. Inesperadamente, a principios de diciembre el Gobierno ya había llegado a un acuerdo con los blanquiazules. La aprobación de la Ley de Ingresos generó la amarga reprobación de los ex integrantes del bloque opositor. Peor escozor produjo la aprobación del presupuesto. ¡Traición!, clamaron los legisladores del PRD. El bloque opositor quedó hecho añicos. En este caso, según explicaron los blanquiazules, se trató de una "cuestión práctica”. Acción Nacional obtuvo ventajas que parecían fuera de su alcance. Al inicio de las negociaciones había solicitado un incremento de $23 \%$ a las transferencias a los gobiernos estatales y municipales. La Secretaría de Hacienda ofreció un terminante 8\%. Y el PAN obtuvo una transacción que, por otra vía, atendía su demanda. En efecto, frente a una Hacienda reservona y cicatera, consiguió que en las transferencias de recursos a sus municipios el presupuesto dejara de privilegiar a los municipios marginados, y los recursos se asignaran de acuerdo con un criterio demográfico cuantitativo. De golpe, el blanquiazul ganaba una tajada sustancial que beneficiaba a las grandes ciudades bajo su control, en detrimento de los ayuntamientos más pobres, mayormente de signo tricolor. Fue una debilidad, un contratiempo que no tardaría en inspirar una sublevación en los gobiernos locales priístas y, a la postre, a la célebre "Ley Bartlett", mediante la cual el gobernador poblano cuestionó el pacto concertado en el ámbito federal y procedió a remitir la cuestión al Congreso estatal, autoridad constitucionalmente competente en la materia, a fin de que decretara "los plazos y modalidades" de los recursos federales transferidos a los municipios. Pero con todo y sublevación se había alcanzado un acuerdo. El 
presupuesto fue aprobado con el apoyo de quien ofreció (o concedió) más. Las declaraciones asépticas de Carlos Medina Plascencia no podrían haber sido más reveladoras: "No existe ninguna alianza con el PRI, ni puede existirla [sic]. Ni pertenecimos al G-4, ni pertenecemos a un bloque con el Gobierno. Se trata simplemente de un acuerdo. Acuerdos y alianzas son cosas distintas".

Es sorprendente. En apenas tres meses y medio las relaciones entre el Gobierno y la oposición habían pasado por tres paradigmas posibles: la oposición unida contra el Gobierno (el asalto del G-4 a la Cámara, entre el 11 de agosto y el 1 de septiembre), el Gobierno en coalición con la oposición (del acuerdo tardío del 31 de agosto al 1 de diciembre), y el bazar de coyuntura (el acuerdo con el PAN, agotado el intento con el PRD), permaneciendo como "terra ignota", aunque promisoria, la mina inagotable representada por los "verdes" y el Partido del Trabajo. Ése habría de ser el signo de la LVII Legislatura.

Fueron varias las iniciativas del Gobierno federal que corrieron la desventura de suscitar una oposición en bloque. Sin embargo, por su significación estratégica y trascendencia hasta nuestros días, conviene recordar dos. La primera fue la tentativa del presidente Zedillo de modificar la Constitución para impulsar un proyecto de derechos y culturas de las comunidades indígenas. La iniciativa produjo de inmediato la airada reacción de los legisladores del sol azteca quienes, a pesar de ser el blanco sistemático de las descalificaciones de los zapatistas, insistieron en que la única forma de respetar los acuerdos de San Andrés consistía en aprobar, sin reparo alguno, la propuesta de la Comisión de Concordia y Pacificación (Cocopa). Ahora bien, los panistas (inconformes con dichos acuerdos y decididos a rechazar la sospechosa propuesta de la Cocopa, determinada por el zapatismo), decidieron "pragmáticamente" no aprobar la iniciativa de Zedillo, en cuya redacción habían 
sido formalmente consultados por el Gobierno, y se abstuvieron de apoyarla. El resultado fue el congelamiento de la propuesta, que nunca fue objeto de dictamen ni pasó a la decisión del pleno.

Igual suerte corrió la iniciativa de reformas constitucionales en materia energética, tendente a abrir las puertas a la iniciativa privada para invertir en la producción y venta de electricidad. El proyecto, que en rigor aportaba una respuesta a las insuficiencias en la producción eléctrica $\mathrm{y}$, sobre todo, a las presiones internacionales para "abrir" el sector, no era esencialmente distinto al que presentó el presidente Fox. Sin embargo, fue enfriado en bloque por los partidos de oposición, incluido el PAN. Además, a decir verdad dicha iniciativa despertó en las filas tricolores una antipatía apenas inhibida por la disciplina. En suma, la iniciativa fue enviada a la congeladora y ni siquiera fue objeto de debate formal. Todos estos casos ilustran el modelo de oposición unida al que hemos hecho referencia.

En rigor, la LVII Legislatura no destacará históricamente por su ineficacia legislativa. En efecto, aunque las más importantes iniciativas recibidas no fueron aprobadas, cuantitativamente tuvo un buen desempeño. La razón se encuentra en la capacidad del Gobierno para crear acuerdos con la oposición en un sinnúmero de materias no sometidas a disputa, como las relativas al medio ambiente, regulación administrativa y reformas a leyes básicas de carácter penal, civil y mercantil. Destaca, en todo caso, la reforma de fin de sexenio, impulsada por el presidente Zedillo, al artículo 115 constitucional, con la idea de fortalecer la autonomía municipal y el desempeño de los ayuntamientos. En todas estas instancias el Gobierno fue capaz de constituir acuerdos amplios con la oposición. De hecho, 70\% de las iniciativas presidenciales, aprobadas a lo largo de la Legislatura, contaron con el voto unánime de la Cámara. Naturalmente, 
todas las iniciativas aprobadas en dicho periodo contaron con el apoyo de al menos dos partidos.

Menos afortunado fue el destino de algunas leyes particularmente difíciles, cuya negociación con el propósito de aprobarlas por consenso resultó fallida, y el Gobierno hubo de conformarse con acuerdos coyunturales. Destaca entre ellas la Ley del Seguro Social. El Gobierno siempre planteó el estado crítico de las finanzas de la seguridad social y las lúgubres perspectivas resultantes. De hecho, el diagnóstico financiero del IMss inspiró la reforma que había introducido el Sistema de Fondos para el Retiro de los trabajadores (Afores). Durante la LVII Legislatura el PRI acordó con el PAN la reforma del Seguro Social. El PRD se opuso argumentando que la medida avanzaba en dirección a la privatización. Sin embargo, invocando las declaraciones de Fidel Velázquez en contra de la reforma, el blanquiazul retiró su apoyo y el tricolor recurrió al PVEM y al PT para obtener finalmente la aprobación. Igual ocurrió con un caso verdaderamente escandaloso cuando, por distintas razones, el PAN y el PRD pretendieron someter a juicio político a connotados priístas, entre ellos a Roberto Madrazo. En este caso, los mismos partidos que apoyaron la reforma a la seguridad social, bloquearon en comisiones el desafuero que haría posibles tales juicios. En estos casos se advierte la exacerbación del pragmatismo, de suerte que los acuerdos entre las fracciones parlamentarias se produjeron uno a uno, desarticuladamente, según el cálculo de las ganancias respectivas.

\section{Conclusiones}

Finalizamos este largo repaso de las peripecias de nuestro federalismo y de las negociaciones políticas, con una doble constatación: la primera se refiere a los factores reales de poder. Como si fuera la adquisición de un pleonasmo, hemos aprendido por décadas que el que puede, puede. El valor 
del régimen federal depende de la fuerza y la vitalidad de las regiones y de la representación de los liderazgos. En un orden piramidal, de partido hegemónico y centralizado, el proyecto federal es un artilugio imposible. La segunda tiene que ver con las grandes fuerzas que determinan los procesos sociales. La centralización de la economía, la vida social y, consecuentemente, la política, responden a factores reales cuyo peso no es contrarrestado con votos y buenas intenciones. El factor determinante para impulsar un nuevo federalismo consiste en la fuerza, la sustancia de los procesos locales. Dicho de otra forma, tendremos una república federal y democrática cuando las fuerzas y oportunidades de las entidades federativas, de la república y de la democracia, sean capaces de resistir a los intereses y proyectos ilustrados del centro.

Se ha comentado ya que el Ejecutivo recurrió también a lo que debió haber sido el camino real: el acuerdo parlamentario con uno o varios partidos para alcanzar la mayoría requerida. Pero se trató de convenios puntuales, que no dieron paso a mayorías perdurables. Como se sabe, la desventaja de dichos arreglos estriba en su costo. Son el resultado de una subasta, en la que el partido efímeramente aliado calcula las ganancias en el corto plazo y vende caro su amor. "Bazar de circunstancia" llamamos a esta modalidad.

En la lógica institucional de la política, a los partidos les convendría que el Congreso funcionara con acuerdos que permitieran el flujo de los programas del Gobierno. La estabilidad y eficacia de las instituciones republicanas debería ser una razón convincente para una oposición "leal" y atenta a las consideraciones de largo plazo. Al contrario, normalmente se impone una lógica pragmática y cortoplacista. Después de todo, a los partidos de oposición les conviene, en el corto plazo, el fracaso rotundo del Gobierno, así implique altos costos sociales y la erosión de las instituciones políticas. En esta línea, los partidos no tendrían interés en la 
aprobación de las iniciativas del Ejecutivo y buscarían, como ha sido el caso, construir acuerdos al margen del Gobierno y "venderlos" con fanfarrias a la opinión.

Por su parte, la lógica pragmática de la política está inspirada en cálculos concretos del costo-beneficio de cada alianza. Corresponde al Gobierno introducir en dichos cálculos incentivos determinantes a favor de mayorías estables. El "toma y daca" puede escandalizar a los espíritus puros. Sin embargo, siempre ha estado en todas partes, en la esencia de las negociaciones parlamentarias. Carece de sustento la idea de que los acuerdos políticos pueden construirse al margen de los intereses, los programas y los sectores sociales que representa cada partido. En los regímenes parlamentarios los pactos perdurables se sustentan en el establecimiento de gobiernos y programas de coalición. $\mathrm{Al}$ partido con mayor peso corresponden las carteras más importantes, mientras que a los aliados de inferior calado, corresponden menos ministerios y de interés inferior. Por otra parte, los partidos coaligados convienen en evitar la aplicación de programas que vulneren los intereses esenciales de cada uno de ellos. Por consiguiente, los gobiernos de coalición suelen dejar en suspenso cambios dramáticos y se convierten más bien en gobiernos de gestión. Complementariamente, los programas de cada uno de los partidos coaligados son atendidos en cada una de las carteras que les corresponde.

Otro incentivo para el acuerdo consiste en la aplicación de ciertos compromisos comunes de cooperación, o al menos de no agresión, en los gobiernos locales o regionales a cargo de los partidos aliados. El punto interesante es que un acuerdo nacional entre diversas fuerzas debería reflejarse en las relaciones entre éstas, en el Gobierno y el Congreso estatal, o en las relaciones entre alcaldes y cabildos. Las alianzas perduran hasta que los intereses esenciales de las partes se enfrentan y no pueden reconciliarse. Por eso los partidos 
coaligados evitan con frecuencia llevar las tensiones hasta un punto de ruptura.

Los acuerdos perdurables no son contrarios a la cultura democrática. En cambio, se inscriben en una línea de construcción de consensos, requisito permanente de la democracia. Sin acuerdo sobre las reglas del juego y las instituciones electorales, sencillamente no podría operar un régimen republicano. Pero los acuerdos exigen la presencia de los atributos propios de la cultura democrática: tolerancia, inclusión, juego dentro de las instituciones y contribución a la preservación del orden. En un horizonte maximalista de oposición, el Gobierno y los partidos terminarían con su capacidad política totalmente vulnerada. Como consecuencia, de acceder al gobierno, las oposiciones recogerían cenizas y experimentarían la misma ingobernabilidad y desgaste devastador. En un horizonte maximalista de consenso, las alternancias quedarían determinadas precisamente por los proyectos y programas políticos propuestos por los contendientes, y por la capacidad de éstos para movilizar la voluntad ciudadana.

Aguilar Camín, H. (2017). La frontera nómada. México: Fondo de Cultura Económica.

Alessio Robles, V. (20I4). La Convención Revolucionaria de Aguascalientes. México: Instituto Nacional de Estudios Históricos de las Revoluciones de México/H. Congreso del Estado de Aguascalientes/Universidad Autónoma de Aguascalientes.

Ávila Espinosa, F. (2017). Breve historia de la Revolución Mexicana. México: Crítica.

Barrón, L. (2004). Historias de la Revolución Mexicana. México: Fondo de Cultura Económica/Centro de Investigación y Docencia Económicas. 
Bibliografía
Brading, D. A. (Comp.) (1985). Caudillos y campesinos en la Revolución Mexicana. México: Fondo de Cultura Económica.

Carpizo,J. (2002). El presidencialismo mexicano. México: Siglo XXI Editores.

Casar, M.A.,y Marván, I. (Coords.) (2002). Gobernar sin mayoría, México 1867-1997. México: Centro de Investigación y Docencia Económicas/Taurus.

Hurtado,J.(200I). El sistema presidencial mexicano. Evolución y perspectivas. México:Universidad de Guadalajara/Fondo de Cultura Económica.

Knight, A. (2015). La revolución cósmica. Utopías, regiones y resultados, México 19/0-1940. México: Fondo de Cultura Económica.

Marván, I. (2017). Cómo hicieron la Constitución de 19/7. México: Secretaría de Cultura/Centro de Investigación y Docencia Económicas/Fondo de Cultura Económica. Mejía Garza, R. M., y Rojas Zamudio, L. P. (20I8). Federalismo(s). El rompecabezas actual. México: Fondo de Cultura Económica.

Mendoza Berrueto, E. (1996). El presidencialismo mexicano. Génesis de un sistema imperfecto. México: El Colegio de la Frontera Norte/Fondo de Cultura Económica.

Meyer, L. (2016). La Revolución Mexicana. México:Tusquets Editores.

Pozas Horcasitas, R. (20I4). Los límites del presidencialismo en las sociedades complejas. México en los años sesenta. México: Universidad Nacional Autónoma de México/ Siglo XXI Editores.

Salazar Ugarte, P. (2017). El Poder Ejecutivo en la Constitución mexicana. Del metaconstitucionalismo a la constelación de autonomías. México: Fondo de Cultura Económica.

Salmerón, P. (2006). La División del Norte. La tierra, los hombres y la historia de un ejército del pueblo. México: Planeta. 
Silva Herzog,J.(2005). Breve historia de la Revolución Mexicana. | Bibliografía México: Fondo de Cultura Económica.

Urquizo, F. L. (1964). Origen del ejército constitucionalista. México: Instituto Nacional de Estudios Históricos de la Revolución Mexicana.

Womack, J. (2017). Zapata y la Revolución Mexicana. México: Fondo de Cultura Económica. 